\section{Commentary: Structural abnormalities after Freestyle full aortic root replacement: Time to accept the facts}

\section{G. Chad Hughes, MD}

The Medtronic Freestyle stentless porcine aortic root bioprosthesis (Medtronic, Inc, Minneapolis, Minn) has been approved by the US Food and Drug Administration since 1997, with studies demonstrating excellent hemodynamic properties as well as low rates of late structural valve deterioration. ${ }^{1}$ Despite this, reports of structural abnormalities after Freestyle implantation, most commonly pseudoaneurysm formation, began to surface as early as $2005,{ }^{2}$ with the first report dedicated entirely to this topic being that of Ozaki and colleagues from Japan, ${ }^{3}$ who described the unique failure mode of degeneration of the porcine aortic root sinus of Valsalva wall, leading to perforation and pseudoaneurysm formation.

Subsequent to that initial report, additional case reports and small series began to emerge over the next several years, $^{4-7}$ and in 2014 our group published the largest study to date at the time examining the issue of Freestyle pseudoaneurysm by aggregating multiple data sets including our institutional series, literature review, and review of the US Food and Drug Administration's Manufacturer and User Facility Device Experience (MAUDE) database, which collects voluntary provider and industry adverse event reports related to medical devices. ${ }^{8}$ Our study suggested a rate of pseudoaneurysm formation as high as nearly 5\% after Freestyle implantation as a full root, with pseudoaneurysms continuing to be observed in late follow-up out to more than 10 years postoperatively. Importantly, in $15 \%$ of cases, the aneurysmal

\footnotetext{
From the Division of Cardiovascular and Thoracic Surgery, Department of Surgery, Duke University Medical Center, Durham, NC.

Disclosures: The author reported no conflicts of interest.

The Journal policy requires editors and reviewers to disclose conflicts of interest and to decline handling or reviewing manuscripts for which they may have a conflict of interest. The editors and reviewers of this article have no conflicts of interest.

Received for publication June 20, 2021; revisions received June 20, 2021; accepted for publication June 21, 2021; available ahead of print June 25, 2021.

Address for reprints: G. Chad Hughes, MD, Division of Thoracic and Cardiovascular Surgery, Department of Surgery, Center for Aortic Disease, Duke University Medical Center, Box 3051 DUMC, Durham, NC 27710 (E-mail: gchad.hughes@ duke.edu).

J Thorac Cardiovasc Surg 2023;165:1301-2

$0022-5223 / \$ 36.00$

Copyright (C) 2021 by The American Association for Thoracic Surgery

https://doi.org/10.1016/j.jtcvs.2021.06.038
}

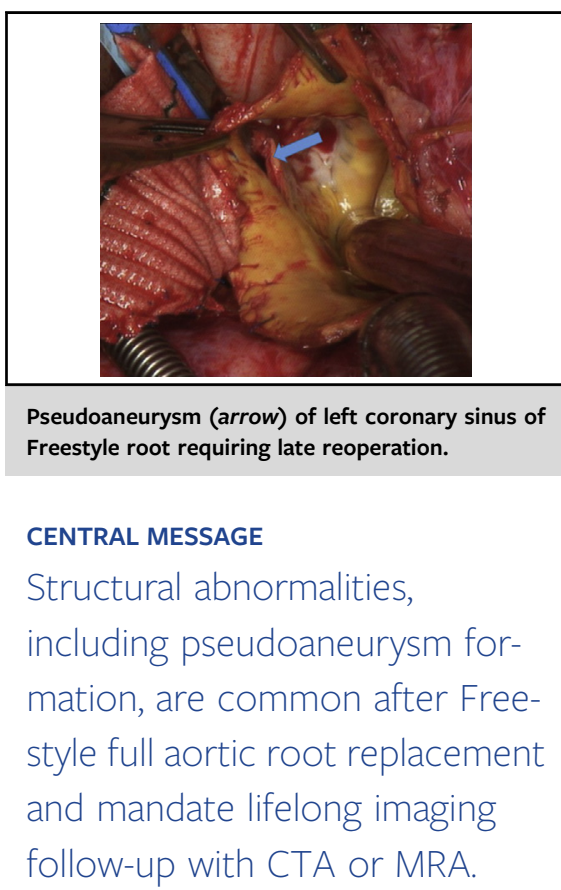

deterioration of the porcine root resulted in patient death. Further, most patients with the complication had minimal or no symptoms. Finally, as the pseudoaneurysms could not be visualized on routine transthoracic echocardiography (TTE), we recommended lifelong surveillance follow-up imaging of these patients with contrast-enhanced computed tomography angiography or magnetic resonance angiography. ${ }^{8,9}$

Following publication of our report, the device manufacturer wrote a letter to the editor ${ }^{10}$ of the journal suggesting that the pseudoaneurysm formation in Freestyle valve full root implants was "extremely rare and does not appear to have a root cause in the manufacturing process." Further, the company representatives went on to insinuate that pseudoaneurysm formation following Freestyle implantation was a technical failure of the implanting surgeons, a response we found quite disappointing and disturbing, given the safety signal our paper suggested based upon collation of multiple data sources, as well as the potentially fatal consequences of the complication. ${ }^{11}$

In the current issue of the Journal, Dagnegård and colleagues $^{12}$ present the largest systematic investigation to date of postoperative structural abnormalities after Freestyle stentless porcine full aortic root implantation. Two hundred fifty-three consecutive patients operated on at Rigshospitalet, Copenhagen University Hospital, and Montreal Heart Institute between 1999 and 2016 underwent postoperative electrocardiogram-gated 4-dimensional cardiac computed tomography (4DCT) of the aortic root late 

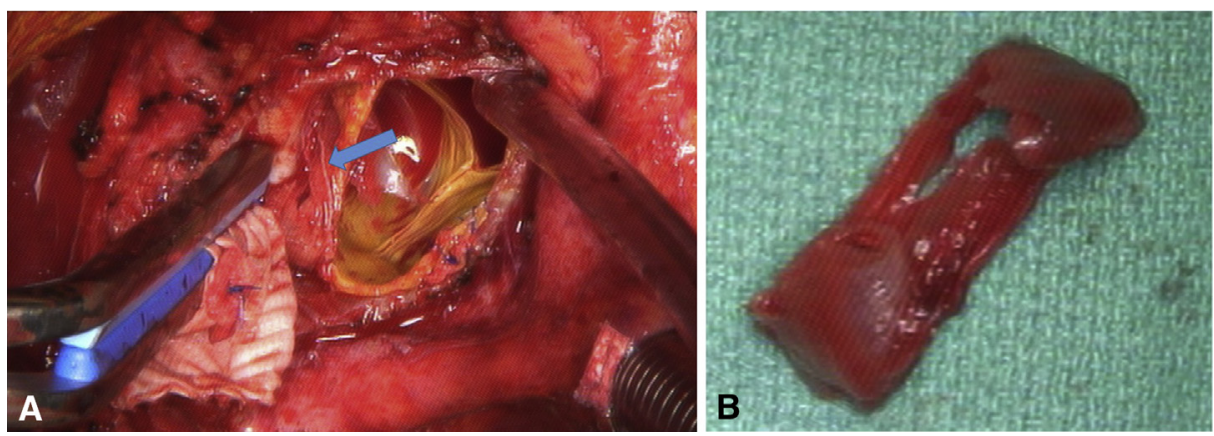

FIGURE 1. A, Intraoperative photographs of a patient requiring reoperation for a pseudoaneurysm of the left coronary sinus of Valsalva of a Freestyle stentless xenograft. Note the large amount of chronic thrombus (arrow) present within the pseudoaneurysm sac. B, Photograph of the sac thrombus. We have observed cerebral embolic events in several patients with Freestyle pseudoaneurysms, including one who presented with a disabling embolic stroke.

postoperatively (3.3-year median interval between surgery and 4DCT). Amazingly, the authors found moderate-tosevere structural abnormalities in $46 \%$ of patients, with $7 \%$ of patients having $>1$ abnormality. The structural abnormalities included pseudoaneurysms in $13 \%$ of patients (nearly 3-fold greater than suggested by our previous work), significant coronary ostial stenosis in $21 \%$ of patients, and leaflet thickening or reduced leaflet motion, a finding that has previously been described both in transcatheter and other surgical bioprosthetic valves, ${ }^{13}$ in $20 \%$.

With regards to pseudoaneurysms specifically, similar to our data, the authors found that the incidence increased steadily over time late after surgery. Further, these patients had the greatest late need for reintervention as well as late stroke (Figure 1). Similar to the findings of our previous study, ${ }^{8}$ TTE was found to be an inadequate screening tool for Freestyle roots, as only a small proportion of the structural abnormalities observed on 4DCT were detected by TTE. Importantly, the structural abnormalities observed were associated with a greater incidence of death, stroke, or myocardial infarction as compared with the group without structural abnormalities.

In summary, the evidence is now undeniable that pseudoaneurysm formation is a serious issue after Medtronic Freestyle implantation as a full root, and the time has come for the manufacturer to stop blaming the issue on the implanting surgeon ${ }^{10}$ and to add to the device instructions for use that surveillance imaging with TTE is inadequate, and that these patients require lifelong imaging follow-up with computed tomography angiography or magnetic resonance angiography. ${ }^{8,9}$ Further, since previous work has suggested an immunologic etiology for these structural failures, ${ }^{14}$ the manufacturer should consider using their many resources to fund research into the apparent origins (immunologic, inadequate fixation, other) of the problem rather than just denying a problem exists.

\section{References}

1. Melina G, De Robertis F, Gaer JA, Angeloni E, El-Hamamsy I, Bahrami T, et al. Long-term survival after xenograft versus homograft aortic root replacement: results from a prospective randomized trial. J Thorac Cardiovasc Surg. 2021; 161:57-65.

2. Bach DS, Kon ND, Dumesnil JG, Sintek CF, Doty DB. Ten-year outcome after aortic valve replacement with Freestyle stentless bioprosthesis. Ann Thorac Surg. 2005;80:480-6.

3. Ozaki N, Hino Y, Hanafusa Y, Yamashita T, Okada K, Tsukube T, et al. Perforation of the Valsalva sinus after implantation of Medtronic Freestyle aortic bioprosthesis. Ann Thorac Surg. 2006;82:2282-5.

4. Butany J, Zhou T, Leong SW, Cunningham KS, Thangaroopan M, Jegatheeswaran A, et al. Inflammation and infection in nine surgically explanted Medtronic Freestyle stentless aortic valves. Cardiovasc Pathol. 2007;16:258-67.

5. Nair V, Law KB, Li AY, Phillips KR, David TE, Butany J. Characterizing the inflammatory reaction in explanted Medtronic Freestyle stentless porcine aortic bioprosthesis over a 6-year period. Cardiovasc Pathol. 2012;21:158-68.

6. Mizuno T. Wall rupture of Medtronic Freestyle stentless porcine aortic root bioprosthesis. Interact Cardiovasc Thorac Surg. 2008;7:1129-30.

7. David TE, Armstrong S, Maganti M, Butany J, Feindel CM, Bos J. Postimplantation morphologic changes of glutaraldehyde-fixed porcine aortic roots and risk of aneurysm and rupture. J Thorac Cardiovasc Surg. 2009;137:94-100.

8. Englum BR, Pavlisko EN, Mack MC, Ganapathi AM, Schechter MA, Hanna JM, et al. Pseudoaneurysm formation after Medtronic Freestyle porcine aortic bioprosthesis implantation: a word of caution. Ann Thorac Surg. 2014;98:2061-7.

9. Iribarne A, Keenan J, Benrashid E, Wang H, Meza JM, Ganapathi A, et al. Imaging surveillance after proximal aortic operations: is it necessary? Ann Thorac Surg. 2017;103:734-41.

10. Vassiliades TA, Kon N, Dion RAE. Regarding Freestyle pseudoaneurysms. Ann Thorac Surg. 2015;100:1507-8.

11. Englum BR, Ganapathi AM, Hughes GC. Reply. Ann Thorac Surg. 2015;100: 1508.

12. Dagnegård HSH, Sigvardsen PE, Ihlemann N, Kofoed KF, El-Hamamsy I, Bekke K, et al. Structural abnormalities after aortic root replacement with stentless xenograft. J Thorac Cardiovasc Surg. 2023;165:1285-97.

13. Makkar RR, Fontana G, Jilaihawi H, Chakravarty T, Kofoed KF, De Backer O, et al. Possible subclinical leaflet thrombosis in bioprosthetic aortic valves. $N$ Engl J Med. 2015;373:2015-24.

14. Naso F, Gandaglia A, Bottio T, Tarzia V, Nottle MB, d'Apice AJ, et al. First quantification of alpha-Gal epitope in current glutaraldehyde-fixed heart valve bioprostheses. Xenotransplantation. 2013;2:252-61. 